\title{
Quantitative determination of the total content $\gamma$-pyrone Compounds in the aerial part of Halenia corniculata by HPLC
}

\author{
(C) Tatiana M. Shishmareva \\ Institute of General and Experimental Biology, Siberian Division, Russian Academy of Sciences. \\ Sakh'yanovoi St., 6. Ulan-Ude, 670047. Buryatia Republic. Russia. \\ Phone:+7 (3012) 43-47-43. E-mail: shishmarevatm@rambler.ru
}

Keywords: $\gamma$-pyrone compounds, xanthones, flavonoids, Halenia corniculata, quantitative determination, HPLC.

\begin{abstract}
This work presents the results of a quantitative determination of the total content of $\gamma$-pyrone compounds in the aerial part of Halenia corniculata using the HPLC method, where the standard samples of 1-hydroxy-2,3,5-trimethoxyxanthone and 1-hydroxy-2,3,4,5-tetramethoxyxanthone. The main active ingredients of $H$. corniculata are xanthones and flavones, and this plant can be used as a possible source of available phenol compounds. To determine the total content of xanthones and flavones in the aerial part of $\mathrm{H}$. corniculata, the hexane, chloroform, and ethyl acetate fractions were studied. During the experiment, 13 compounds were found in the hexane fraction of $H$. corniculata, among which the content of 1-hydroxy-2,3,4,5tetramethoxyxanthone is $43.07 \%$ of the mass of the hexane fraction and $1.44 \%$ of the mass of absolutely dry raw materials, and 1-hydroxy-2,3,5-trimethoxyxanthone $-22.20 \%$ by weight of the hexane fraction and $0.74 \%$ by weight of absolutely dry raw materials. In the chloroform fraction of $H$. corniculata, 17 compounds were found, and 1-hydroxy-2,3,4,5-tetramethoxyxanthone $(6.26 \%$ of the mass of the chloroform fraction and $0.20 \%$ of the mass of absolutely dry raw materials) and 1-hydroxy-2,3,5-trimethoxyxanthone ( $4.22 \%$ by weight of the chloroform fraction and $0.13 \%$ by weight of absolutely dry raw materials). In the study of the ethyl acetate fraction of $H$. corniculata, 14 compounds were found, among which 1 component was identified - luteolin, the content of which is $68.26 \%$ of the weight of the ethyl acetate fraction and $2.41 \%$ of the weight of absolutely dry raw material. The total content of $\gamma$-pyrone compounds in the aerial part of $H$. corniculata is $4.92 \%$ (based on the weight of the absolute dry raw material).
\end{abstract}

\section{References}

[1] T.M. Shishmareva, L.M. Tankhaeva, D.N. Olennikov, and S.M. Nikolaev. Isolation, chemical modification and cholagogic action of some derivatives of xanthones from Halenia corniculata. Butlerov Communications. 2011. Vol.28. No.20. P.58-67. ROI: jbc-02/11-28-20-58

[2] T.M. Shishmareva, and D.N. Olennikov. $\gamma$-Pyrone compounds of Halenia species. Butlerov Communications. 2012. Vol.32. No.12. P.74-79. ROI: jbc-02/12-32-12-74

[3] T.M. Shishmareva, and V.M. Shishmarev. Chemical composition and ecological and biological characteristics of Halenia corniculata. Butlerov Communications. 2017. Vol.49. No.1. P.153-157. DOI: 10.37952/ROI-jbc-01/17-49-1-153

[4] Plant resources of the USSR. Flowering plants, their chemical composition, use. Families Caprifociaceae - Plantaginaceae. Leningrad. 1990. 325p. (russian)

[5] Keys to plants of Buryatia. comp. O.A. Anenkhonov, T.D. Pykhalova, K.I. Osipov, I.R. Sekulich, N.K. Badmaeva, B.B. Namzalov, L.V. Krivobokov, M.S. Munkueva, A.V. Sutkin, D.Ya. Tubshinova. UlanUde. 2001. 672p. (russian)

[6] A.F. Gammerman, V.B. Semichov. Dictionary of Tibetan-Latin-Russian names of medicinal raw materials used in Indo-Tibetan medicine. Ulan-Ude. 1963.162p. (russian)

[7] A.N. Kudrin, S.M. Nikolaev, K.S. Lonshakova, Z.G. Sambueva. Membrane stabilizing effect of plant phenols. Abstracts. Report 5th Congress of Pharmacologists of the Ukrainian SSR. Zaporizhzhia. 1985. P.86-87. (russian)

[8] T.M. Mikhailova. Isolation and chemical modification of natural xanthone compounds: Abstract of PhD Thesis. Ulan-Ude. 2004. 22p. (russian) 
QUANTITATIVE DETERMINATION OF THE TOTAL CONTENT I-PYRONE COMPOUNDS IN THE AERIAL... 116-120

[9] A.F. Gammerman, K.F. Blinova, A.N. Badmaev. Antimicrobial properties of medicinal plants of Tibetan medicine. Phytoncides, their biological role and importance for medicine and the national economy. Kiev. 1967. P.107-114.

[10] T.M. Shishmareva, D.N. Olennikov. Chemical composition and biological activity of the genus Halenia (review). Chemistry of Plant Raw Materials. 2013. No.3. P.5-16. (russian)

[11] T.M. Shishmareva, O.G. Potanina, L.M. Tankhaeva, D.N. Olennikov. Pharmacognostic characteristics of the aerial part of horned galena. Chemistry of Plant Raw Materials. 2006. No.3. P.39-47. (russian) 